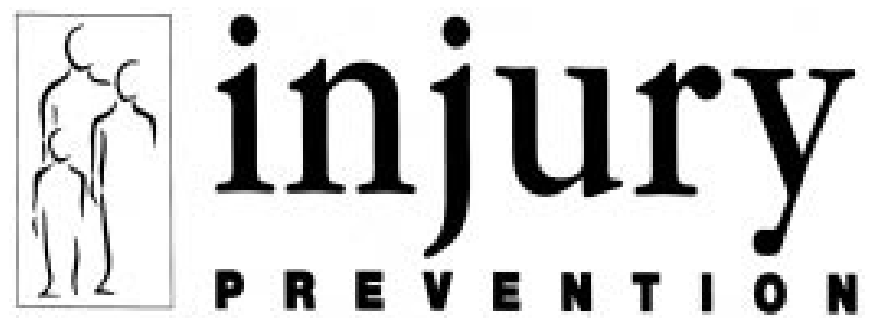

\title{
Editorial
}

\section{Preventing terrorist attacks}

One of the many drawbacks of quarterly journals is that material is often not timely. Tragically, the events in the US have an eerie, timeless quality. As I write this editorial, the terrorist attacks are only a week old. No one needs a reminder of the grisly, almost unbelievable images. But as editor of a journal called Injury Prevention I feel compelled to ask how this might have been prevented? It is all too easy to blame lax airport security, or the policies of countries such as my own that allegedly permit terrorist organizations to raise money on their soil. Clearly, such madness must be remedied. But beyond saying this I have little wisdom to share. We need to better understand what drives the terrorists, and somehow this seems to go beyond politics, the inequities of history, or perceived threats to religion. No matter what, deep down I cannot accept that acts of revenge that involve the deaths of other innocent civilians is the answer. Instead, I advocate a more cautious and reasoned response, as do some within Bush administration itself. No doubt many will dismiss inaction as foolish. I trust, however, that no one will disagree that whatever else we do, we must pray hard and work harder for world peace. On behalf of the entire editorial board I extend our deepest sympathies to all whose loved ones were killed or injured in these senseless, unfathomable acts.

\section{Helping the helpers}

In previous editorials I have written about risk factors for injuries that seem "ubiquitous". By this I mean that they are found in most countries and affect most, if not all, types of injury. A good example is alcohol. In this column I comment on a related phenomenon, not as a risk for injury but as a risk for failing to implement preventive measures adequately.

It has been repeatedly stated that the quintessential problem in injury prevention is that so much of what we know to be effective is not applied, or not applied fully. Rivara and others have estimated that if we were able to fully implement all we know, there would be about 30\% fewer injury deaths among children. I have no doubt the figure for adults would be the same, and possibly even higher, and there is no reason to think that the same shortfall is not seen with respect to non-fatal injuries.

Thus, injury prevention presents a sharp contrast to other health problems. Although in all instances investigators seek to find causes or remedies, in the case of "ordinary diseases" once either of these meets with success, it is rarely a problem to take the next steps to fully harvest the fruits of the research. For example, it is difficult to imagine the results of a successful study of a drug to prevent or treat a disease being ignored. Its manufacturers, clinicians, and occasionally patients will press for the drug's general adoption.
Unfortunately, there are no parallels in injury prevention. There is no equivalent of a manufacturer with an economic motive to move forward. True, for some products such as smoke detectors, tap water valves, or protective sports equipment, there are profits to be made and manufacturers have a financial stake in having their product widely adopted. But this journal and others like it have nothing like the pages upon pages of attractive (and lucrative) ads that are sprinkled throughout mainstream medical journals promoting a new drug or a variant of an old one. Part of the reason we have no advertisements is that it is not clear who the consumer is, even if it could be assumed that they read the journal in question. The sad fact is that few safety groups, with some notable exceptions like MADD, are like those who vigorously demand better therapies or preventive measures.

Whatever the reasons, the problem is all too evident. We have been slow to realise that the implementation issue requires the same painstaking, tedious, step-by-step elements of research as have been devoted to discovering what works. Three papers in this issue and another in a previous issue illustrate the sort of studies likely to be needed before further progress can be made towards implementation. I trust the authors would agree that none of these are as rigorous as we might like, but these reports are critical first steps on which others should quickly build. 
The paper in our September issue by Coyne-Beasley and her colleagues ( $p$ 200) found that even in the hands of law enforcement officers, trigger locks are used far less often than we might expect. Although it is doubtful that police are a good sample of the general population of gun users, the reasons they give for not using gun locks are illuminating and may well have broader applicability.

In this issue, Begg's paper describes how effective a graduated driver licensing (GDL) system can be and identifies one of the most useful components (p 292). All well and good. But, as Steenburgen notes, if parents, police, or the judiciary fail to do what is needed to fully implement a GDL system, there is no reason to expect it will accomplish the desired goals. We need to better understand the difficulties these key partners have and how to eliminate or minimize the difficulties before we will be successful.

A variation on this need to know more about the links in the chain from what works to making it work, is provided by Jaye et al (p 302). Tap water scalds is an issue that Safe Kids Canada has begun to tackle. In doing so, they like Jaye and her colleagues, uncovered a myriad of barriers. In the New Zealand example the focus is on the attitudes of plumbers. For Safe Kids Canada other actors appeared on the stage.

It is one thing to say that the solution is simple- - see to it that the water coming from taps are at "safe" temperatures by lowering the setting on heating tanks. It is another to persuade others to work towards this goal. Not everyone has access to hot water heaters, or the courage to fiddle with the settings. They need help. And there continues to be strong opposition from those who are convinced that lowering temperatures will increase the chances of legionella infection. Although I have no doubt the microbe grows better in cooler than it does in hotter water, I know of no evidence that this translates into more disease. Nevertheless, those who hold this belief are part of the chain; they must be persuaded that lower temperatures are safe before they can be expected to cooperate.

Each of the examples point in the same direction: that the safety community alone cannot succeed without enlisting the help of others. Some are potential allies whose support we need to enlist; others represent obstacles whose opposition needs to be overcome. An early report in this journal noted that clerks selling bike helmets who do not understand the safety issues may either fail to promote their use or give bad advice. Similarly, as Chamberlain and Solomon note ( $p$ 272), police officers who are not convinced speeding or drunk driving are as serious as robbery may resent ticketing offenders and divert their attention elsewhere. Similar examples can be found wherever we look.

The question some potential allies may ask is, "Apart from doing good for others, why should I sacrifice time, effort or income, to help achieve injury prevention goals?" In an ideal world no such sacrifice would be required. In fact, even in the imperfect realms in which most of us live, it is conceivable that an enlightened government would make it a policy to provide subsidies, or, if necessary, penalties or both, to facilitate such cooperation. One way or another we need to recognize how essential the help of others is to achieve success in preventing injuries. To do so we must find ways to help the helpers.

B PLESS Editor

\section{In this issue: the editor's two cents}

As a multidisciplinary journal we believe it important to document the dimensions of a problem from the perspective of colleagues in other disciplines. In the Special Feature (p 272) in this issue, Chamberlain and Solomon, both lawyers, set to rest the myth that the hardcore drinking driver is the underlying problem in the drunk driving epidemic. As they note, focusing only or mainly on the hardcore, repeat offender tends to marginalise the problem. Yet this is often done and is used by some as an excuse to inhibit the sort of legislation so badly needed,

The authors' findings make it clear that a large percentage of so-called social drinkers have blood alcohol concentrations in the hardcore range, and that infrequent drinkers have a much higher relative risk of a crash than do heavy drinkers with the same concentrations. Their recommendation that we discard value labels such as "social drinkers" and "hardcore drinkers" is an excellent one. If adopted by legislators this would go a long way to improving the grave situation in Canada and elsewhere.

Understandably, most injury research focuses on causes and how to prevent their consequences. The third part of the classic prevention trilogy, tertiary prevention, is too often overlooked. Thus, we welcome papers that remind readers of the consequences of injuries, physical, psychological, and economic, and how these too might be prevented.

One such paper is that of Ward et al (p 297). It examines an old, but still unresolved question - what happens when children or adolescents are exposed to violence? I was surprised at how prevalent such exposure is in the study setting and it was also unexpected to learn that the psychological consequences of this experience differ depending on the type of violence to which the adolescent is exposed. Regardless of type, however, the mental health problems that so often follow are sustained and have wide effects. In light of these findings, there is an urgent need to know more about the effectiveness of violence prevention programs. So far, too few such programs have been evaluated.

Another side of the coin (can there be more than two?) is the report by Hammig et al (p 312) regarding predictors of injury from fighting. Among adolescent males involved in fights in the preceding year, $47 \%$ injured others and $18 \%$ were themselves injured. The greatest dangers were associated with fights that took place in groups or with strangers or those where a weapon had been used. Here again, solutions are not evident. They may, however, prove to be remarkably similar to those required to reduce bullying or exposure to violence.

Consistent with the theme of this issue's editorial is the contribution by Hemenway et al ( $\mathrm{p}$ 282) describing US national attitudes concerning gun carrying. This exemplifies the importance of knowing all or many of the ingredients in a large puzzle before one can hope to solve it. The puzzle in this instance is death and injury from handguns, especially in the US. In this study, two surveys three years apart showed that Americans feel less safe as gun carrying increases. The paper reports growing opposition to permissive practices with respect to possession of guns and growing sentiment in 
support of prohibitions against carrying weapons in public places. Not wishing to oversimplify a complex issue, given the public support this study indicates, it should now be somewhat easier to persuade policy makers, the judiciary, and police to adopt stronger measures.

The report by Steenbergen et al (p 286) is yet another timely reminder that having an efficacious preventive strategy is one thing; ensuring that it is fully implemented, quite another. In this instance, the focus is on a graduated driver licence program to which the barriers reported appear widespread. They range from lack of awareness of some restrictions by parents and drivers, to difficulties with enforcement of the law's provisions because of the views of police officers and judges. Assuming these barriers are found elsewhere, as noted in my editorial, it is evident that to succeed in this arena as in so many others, we need to enlist the help of others. How to do so remains poorly understood. Even heavy handed legislative measures will be less effective than we expect if barriers to their implementation are not removed.

A companion piece to the previous paper (Begg et al; $\mathrm{p}$ 292) provides further evidence that graduated driver licensing systems, when they include components such as night time curfews, restriction on the carrying of young passengers, and a low blood alcohol limit, are highly effective. This study uses a pre-post design to conclude that one element in particular - the night time curfew-contributes heavily to reductions in serious crashes in young drivers. Teasing out the effective components of a preventive program is a worthy exercise and should be done more often, if not routinely when such programs are being assessed.

Another facet of the need to better understand each of the steps needed to successfully implement an intervention is exemplified by the paper by Jaye et al (p 302). This report is based on a qualitative study of the views and behaviours of plumbers in New Zealand towards achieving safe hot tap water. Scalds are a growing concern and affect the elderly as well as the very young. Although many scalds are from boiled liquids, a significant proportion come from tap water that is heated more than is needed. The solution appears simple-lower the temperature of heating tanks. But it is evident that unless the views of key links in the chain are taken into account, in this case those of plumbers, trying achieve the goal will have limited success.

We have published many papers addressing economic issues related to injury prevention in part because I still harbour the possibly foolish notion that policy makers are influenced by cost savings, especially when these savings are large. In addition to illustrating the magnitude of savings from a smoke alarm distribution program, the report by Haddix et al (p 276) reminds us that most effective prevention programs combine education with a passive measure, preferably one that is free. In this case that measure is alarms given to families in high risk areas. The total net savings from this approach are such that it is difficult to imagine legislators concerned about reducing costs to their community, quite apart from reducing death and suffering, ignoring this potential bonanza.

Falls are one of the most common injuries involving all age groups, and although many have relatively minor consequences, some can be extremely serious. Apart from falls in the elderly this is a neglected research topic and thus the report by Ellis and Trent is welcome but perplexing ( $p$ 316). Do fall injuries differ among races and if so why? The answer to the first question is, yes, at least in California they do, but perhaps not in the direction one might predict. Same level falls resulting in hospitalizations are almost four times higher among whites than among other racial groups studied. They are also more likely to be serious and, not surprisingly, involve a large consumption of hospital resources. What is not at all clear is why this difference exists. The usual culprit, differences in exposure, may well be implicated but the reasons are not obvious. Nor am I convinced that better prevention will be achieved by targeting the high risk group. The jury is still out.

Hendricks and Adekoya's paper (p 307) highlights some unexpected dangers of farm animals. Using a large survey in the US, the results showed that a majority of those injured were farm residents (no surprise). But as a city dweller, I had not anticipated the number that were work related or that nearly half involved children under age 10 . I was also surprised to learn that $37 \%$ involved horses and $31 \%$ cattle - beasts that I thought were relatively safe. Here again, the problem is clear but the solution is not. Readers' suggestions would be most welcome.

One important function of this journal is to help advance the field in every respect, including refining research tools. Thus, this issue includes two important methodological contributions. Based on other publications, it seemed reasonable to assume that a useful supplementary source of data, especially for unusual injuries such as drowning, is newspaper reports. However, the findings of Baullinger et al (p 339) suggests otherwise. After comparing newspaper reports with death certificates and hospital discharge data, they conclude that at least in the case of drowning, reliance on newspaper reports alone would greatly underestimate the size of the problem. Not only would the resulting morbidity and mortality be minimized, but so would several important risk factors. The moral of this story is not to make ready assumptions about data sources no matter what their reputation may be.

The other methodological contribution has a more encouraging bottom line. The report by LeMier, Cummings, and West ( $\mathrm{p}$ 334) shows that E coded hospital discharge records can be remarkably accurate. In particular, two components of the E code, the mechanism and intent of injury, agree well with other data sources. This is good news indeed. All that remains is to persuade hospitals everywhere to proceed quickly to require $\mathrm{E}$ codes for every injury discharge. Here too, the problem is not knowing what to do, but how to get it accomplished. How reluctant hospitals can be persuaded is unclear, but for those hospitals who use the argument that such coding is inaccurate as an excuse for hanging back, this paper should be of great help.

Although case reports are of limited value, there are instances when they serve a vital purpose. In a previous issue we published one such series drawing attention to a new hazard: self strangulation from cloth towel dispensers. This attracted much press attention. In this issue we publish a case series to bring to our readers attention a problem that has been recognised previously but which remains underestimated-the danger to young children from reversing vehicles. These tragic events occur most often in the child's own driveway, but the report by Mayr et al (p 327) suggests that farmyards are also involved. Most of these injuries are serious and likely to have immense psychological effects on the driver.

David and Goel's report ( $\mathrm{p}$ 329) about hand injuries to sugar cane crushers in India is also illuminating because it reminds us that in many societies-perhaps all-most injuries are still viewed as bad luck or God's will. This may be less surprising than the reluctance of so many of these workers to take protective measures, such as wearing gloves or perceiving the need for safer machines. This complacency echoes the attitude of many workers in western society as well. 